\title{
Looking upstream: enhancers of child nutritional status in post-flood rural settings
}

Jose Manuel Rodriguez-Llanes, Shishir Ranjan-Dash, Alok Mukhopadhyay, Debarati Guha-Sapir

Background. Child undernutrition and flooding are highly prevalent public health issues in many developing countries. Yet we have little understanding of preventive strategies for effective coping in these circumstances. Education has been recently highlighted as key to reduce the societal impacts of extreme weather events under climate change, but there is a lack of studies assessing to what extent parental education may prevent post-flood child undernutrition. Methods and materials. One year after large floods in 2008, we conducted a two-stage cluster population-based survey of 6-59 months children inhabiting flooded and non-flooded communities of Jagatsinghpur district, Odisha (India), and collected anthropometric measurements on children along with child, parental and household level variables through face-to-face interviews. Using multivariate logistic regression models, we examined separately the effect of maternal and paternal education and other risk factors (mainly income, socio-demographic, and child and mother variables) on stunting and wasting in children from households inhabiting recurrently flooded communities (2006 and 2008; $n=299$ ). As a comparison, separate analyses on children in non-flooded communities were carried out $(n=385)$. All analyses were adjusted by income as additional robustness check. Results. Overall, fathers with at least completed middle education (up to 14 years of age and compulsory in India) had an advantage in protecting their children from child wasting and stunting. For child stunting, the clearest result was a 100 to $200 \%$ lower prevalence associated with at least paternal secondary schooling (compared to no schooling) in flooded-areas. Again, only in flooded communities, an increase in per capita annual household income of 1,000 rupees was associated to a 4.7-4.9\% lower prevalence of child stunting. For child wasting and only in flooded areas, delayed motherhood was associated to better nutritional outcomes (3.4\% lower prevalence per year). In flooded communities, households dedicated to activities other than agriculture, a 50 to $51 \%$ lower prevalence of child wasting was estimated, suggesting farmers and fishermen as the most vulnerable livelihoods under flooding. In flooded areas, lower rank castes were at higher odds of both child wasting and stunting. Conclusions. In the short-term, protracted nutritional response in the aftermath of floods should be urgently implemented and target agricultural livelihoods and low-rank castes. Education 
promotion and schooling up to 14 years should have positive impacts on improving children nutritional health in the long run, especially under flooding. Policies effectively helping sustainable livelihood economic development and delayed motherhood are also recommended. 


\section{Looking upstream: enhancers of child nutritional status in 2 post-flood rural settings}

3 Jose M Rodriguez-Llanes ${ }^{1}$, Shishir Ranjan-Dash ${ }^{2,3}$, Alok Mukhopadhyay4, Debarati Guha-Sapir ${ }^{1}$

4

$5{ }^{1}$ Centre for Research on the Epidemiology of Disasters, Institute of Health and Society, Université

6 catholique de Louvain, Brussels, Belgium

$7 \quad 2$ Siksha 'O' Anusandhan University, Bhubaneswar, India

$8{ }^{3}$ Tata Trusts, Mumbai, India

$9 \quad{ }^{4}$ Voluntary Health Association of India, New Delhi, India

11 Corresponding Author:

12 Jose M Rodriguez-Llanes ${ }^{1}$

1330 Clos Chapelle-aux-Champs, Brussels, 1300, Belgium

14 Email address: jose.rodriguez@uclouvain.be 


\section{Abstract}

25 Background. Child undernutrition and flooding are highly prevalent public health issues in many developing countries. Yet we have little understanding of preventive strategies for effective coping in these circumstances. Education has been recently highlighted as key to reduce the societal impacts of extreme weather events under climate change, but there is a lack of studies assessing to what extent parental education may prevent post-flood child undernutrition.

Methods and materials. One year after large floods in 2008, we conducted a two-stage cluster population-based survey of 6-59 months children inhabiting flooded and non-flooded communities of Jagatsinghpur district, Odisha (India), and collected anthropometric measurements on children along with child, parental and household level variables through face-to-face interviews. Using multivariate logistic regression models, we examined separately the effect of maternal and paternal education and other risk factors (mainly income, socio-demographic, and child and mother variables) on stunting and wasting in children from households inhabiting recurrently flooded communities (2006 and 2008; $n=$ 299). As a comparison, separate analyses on children in non-flooded communities were carried out $(n=$ 385). All analyses were adjusted by income as additional robustness check.

Results. Overall, fathers with at least completed middle education (up to 14 years of age and compulsory in India) had an advantage in protecting their children from child wasting and stunting. For child stunting, the clearest result was a 100 to $200 \%$ lower prevalence associated with at least paternal secondary schooling (compared to no schooling) in flooded-areas. Again, only in flooded communities, an increase in per capita annual household income of 1,000 rupees was associated to a $4.7-4.9 \%$ lower prevalence of child stunting. For child wasting and only in flooded areas, delayed motherhood was associated to better nutritional outcomes (3.4\% lower prevalence per year). In flooded communities, households dedicated to activities other than agriculture, a 50 to $51 \%$ lower prevalence of child wasting was estimated, suggesting farmers and fishermen as the most vulnerable livelihoods under flooding. In flooded areas, lower rank castes were at higher odds of both child wasting and stunting. Conclusions. In the short-term, protracted nutritional response in the aftermath of floods should be urgently implemented and target agricultural livelihoods and low-rank castes. Education promotion and schooling up to 14 years should have positive impacts on improving children nutritional health in the long run, especially under flooding. Policies effectively helping sustainable livelihood economic development and delayed motherhood are also recommended. 


\section{Introduction}

57 Among all the disaster risks associated to a warming climate, flooding has become the most frequent and since the nineties it has been affecting grosso modo 100 million people a year. This is more than any other disaster type worldwide, climate-related or not (EMDAT, 2015). Yet and relative to their importance, the health consequences of flooding have been rarely investigated (Ahern et al., 2005; Alderman et al., 2012). Even if, at the time of writing, an equivalent $37.8 \%$ (ie, 2.8 billion people) of the current world population was affected by floods in the past 25 years, little serious actions are being taken.

64

Education has been recently stressed as one key to reduce the societal impacts of climate change (Striessnig, Lutz \& Patt, 2013). The study of educational attainment as a promotor of disaster resilience recently received substantive attention in a collection of 11 papers (Muttarak \& Lutz, 2014). The results of this special issue are a convincing step forward. These studies were undertaken in different countries and regions, and targeted relevant outcomes in different phases of the disaster cycle in populations exposed to diverse climate-related hazards. Overall, they found that higher-educated groups avoided high-risk areas to settle, were better prepared, reacted more efficiently to early warnings and had lessen impacts on health and social variables, which indicated according to the authors better coping and recovery in these groups (Muttarak \& Lutz, 2014). For the particular case of flooding, the evidence on the role of education as a promotor of positive health outcomes is scant and contentious (Lowe, Ebi \& Forsberg, 2013). But what are the plausible pathways linking more education to health improvements? Indeed, formal education is crucial for acquisition and processing of information (eg, literacy), improvement of cognitive abilities, decision making and long-term planning, and generally it leads to securing skilled jobs and ultimately higher income and better health (briefly reviewed in Striessnig, Lutz \& Patt, 2013 and Lindeboom, Nozal \& Klaauw, 2009).

The transgenerational effects of education on health have received substantial attention. Although the effect of maternal education on child stunting and general child health has been studied (Milman et al., 2005; Lindeboom, Nozal \& Klaauw, 2009), the effect of paternal education on child health has been more rarely examined (Moestue \& Huttly, 2008; Semba et al., 2008). Assessing the extent to which father education affects child's health is an important step to understand the relative contribution of fathers to the family wellbeing. Considering father's education is also a premise to further study the 
85

86

87 88

89

90

91

92

93

94

95

96

97

98

99

100

101

102

103

104

105

106

107

108

109

110

111

112

113

114

synergies between father and mother education levels in the promotion of child's health (Semba et al., 2008).

Adequate child nutrition is a key indicator of wellbeing and development of particular importance in developing countries (Black et al., 2013). Nevertheless, studies connecting flood-exposure to the nutritional status of children have been rare and none of them considered the role of father education in preventing the health impacts of floods among children (Phalkey et al., 2015). To the best of our knowledge, no study to date has investigated particularly the role of parental education on child's nutritional status in post-flood settings. We only found one study which investigated the sole effect of mother education, not father education, on malaria parasitemia in Sub-Saharan children (Siri, 2014). Importantly, no study has looked at the association of education on child wasting, let alone in the context of floods. The investigation of child wasting is relevant as evidence suggest that stunting and wasting represent different processes of undernutrition (Ricci \& Becker, 1996). Recent evidence suggests that exposure to floods can be associated to increases in both child stunting (Rodriguez-Llanes et al., 2011) and child wasting (Rodriguez-Llanes et al., 2016) and thus both deserve attention in postflood settings.

The large floods occurring in rural Odisha, India in September 2008 produced massive damage to agriculture, water and sanitation, communication networks and severe disruption to the normal functioning of the entire rural society at large (Government of Orissa, 2008). As part of an integrated project to investigate the health, social, and economic impacts of disasters, we carefully planned and conducted in September 2009 a representative survey of children affected and non-affected by these floods in 265 communities. To get further insight into prevention strategies for the health impacts of floods, which are absent in the literature (Bouzid, Hooper \& Hunter, 2013) we examined in this study the effect of maternal and paternal education and other risk factors on stunting and wasting in children from families living in flooded and non-flooded communities.

\section{Materials \& Methods}

\section{Design and sample}

Jagatsinghpur is a coastal district of the state of Odisha, located within the Bay of Bengal, India. The district's population is around one million, 90\% of which inhabit rural areas (Census of India, 2011). The region is located in a large and fertile flood plain, crossed by large rivers, which makes it very attractive 
115 for fishing activities, livestock rearing and crop farming. However, this land is also regularly affected by

116 heavy monsoons which often produce flooding. In the last decade, Jagatsinghpur has been hardly hit by 117 five major floods, including coastal flooding associated to cyclone Paradip (05B) in 1999, followed by 118 heavy rain floods in 2001, 2003, 2006 and the latest flood occurring prior our investigation, which took 119 place in mid-September 2008 (Government of Orissa, 2008).

120 We conducted a population-based survey one year after the 2008 flooding in rural Jagatsinghpur 121 district, Odisha, India. A two-stage cluster survey was necessary to obtain a probability sample of 122 children 6 to 59 months of age in 265 villages from four severely flood-affected blocks of the district 123 (Kujang, Biridi, Balikuda and Tirtol). Overall, 122 of these were flooded and 143 non-flooded in

124 September 2008. The percentage of households flooded in each village was obtained for 2006 and 2008 events from OSDMA data (OSDMA, 2009; Fig. 1).

126 We used a two-stage cluster design to select our sample as our population of interest was clustered in 127 villages and the information on the population was scant (Groves et al., 2009). In this study, the Primary 128 Sampling Units (PSUs) were the villages and the children were the Secondary Sampling Unit (SSU). A 30 129 (PSU) by 30 (SSU) design, which should provide a probability sample of 900 children, was fixed. We 130 initially enumerated the 265 villages along with each village population size projected for 2009 from 131 census data (Census of India, 2001), and subsequently 30 clusters from 29 villages were selected. This

132 first selection was done using Probability Proportionate to Size (PPS) sampling with replacement (ie, one 133 large village was selected twice). This method picks up randomly villages, but the chances of selection 134 are proportional to the size of the village, with selection probabilities favoring larger villages (Groves et 135 al., 2009). At the second stage a fixed number of children (ie, 30) are selected by cluster, independently 136 of village size. The result is that chances are compensated with equal probabilities of selection of any 137 eligible child listed in the sampling frame (Groves et al., 2009). Importantly, an updated list of eligible children was obtained from the ICDS centers (1 ICDS center for every 1,000 inhabitants) and validated with the ward members of each village. A total 3,671 eligible children were listed from 29 villages within a month prior training and piloting of the survey instrument. Once the lists compiled, it was detected that three flooded villages (Korana, Jamphar and Raghunathpur) and two non-flooded (Muthapada,

142 Sureilo) did not have enough eligible children (ie, less than 30). We created 5 new clusters by merging 143 the list of children in each of these 5 villages $(n=280)$ with those of the closest non-selected flooded or non-flooded village, respectively, of our list (Fig. 1). Finally, thirty children per cluster were randomly 145 selected. 
146 Figure 1: Study site, eligible villages and original sample of flooded and non-flooded villages in 147 Jagatsinghpur district, Odisha, India.

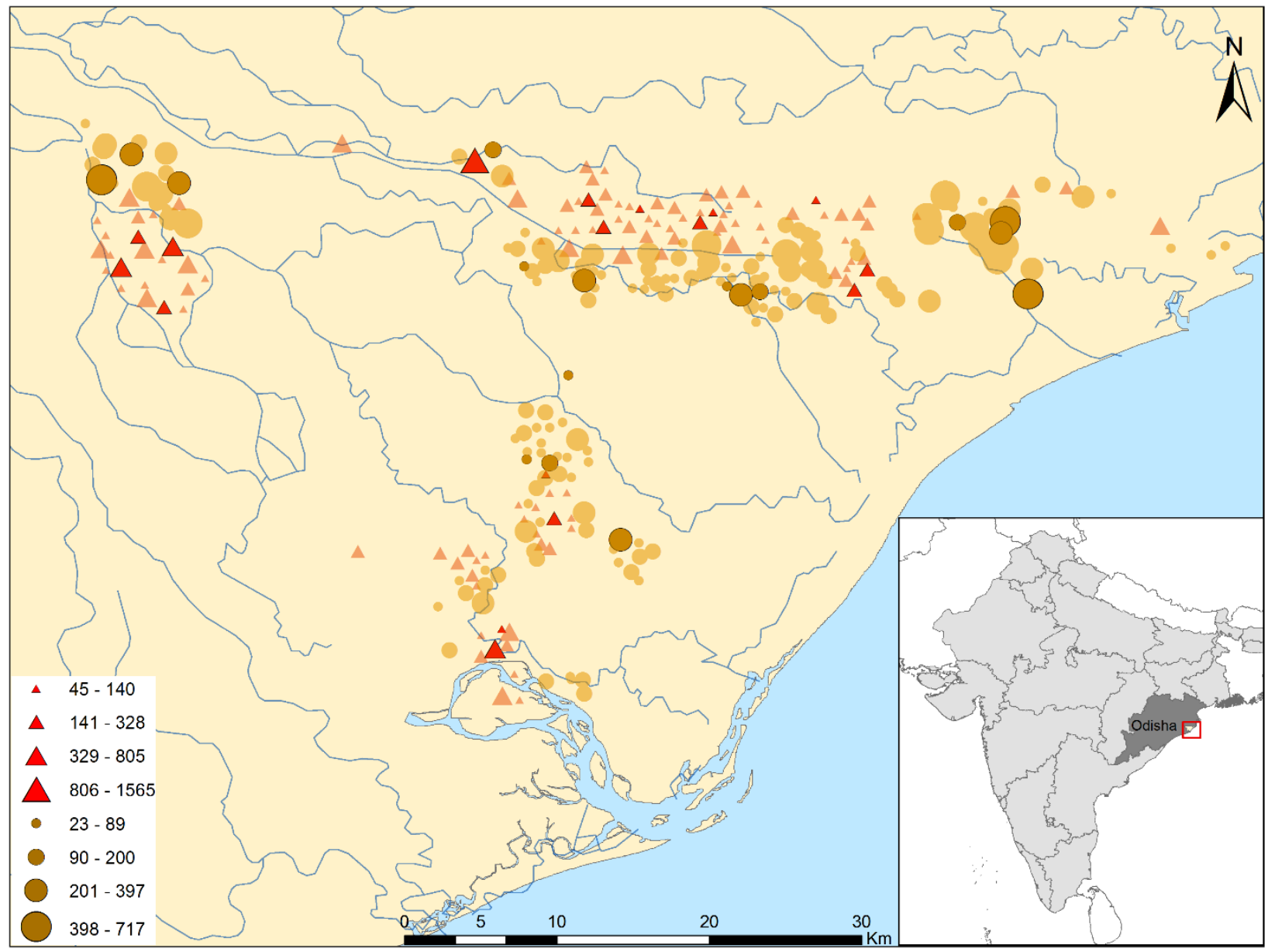

Triangles represent flooded villages; circles those non-flooded. Size of polygons is proportionate to village size as measured by number of households (see map legend). Polygons overimpressed identified villages selected.

\section{Ethical approval}

153

This study was approved by the Community Health Ethics Committee, Voluntary Health Association of India, New Delhi. Persons eligible to participate in the study were not offered any monetary incentive.

Written informed consent was obtained for every head of household visited. In case the respondent was an illiterate, we asked a literate person from the community to read out the consent form and explain it to the head of the family. Then we obtained the thumb impression of the respondent. In those case, the person who readout the consent form also signed as a witness. Research procedures were consistent with the Declaration of Helsinki (1997). Interviews were administered after obtaining informed consent. 
160 The protocol was reviewed by a small group of scientists who had experience working with survivors of

161 natural disasters and amended based on their recommendations.

162 Data collection: instruments and measures

163 Our survey instrument was adapted from the core one developed and approved by a multidisciplinary 164 consortium of researchers from the MICRODIS project. The instrument development was based on 165 interim literature reviews, and follows the UNICEF conceptual framework on child malnutrition (UNICEF, 166 1997). The questionnaire was validated prior to our study in research sites in India, Indonesia, The 167 Philippines, Vietnam and the UK. We collected background information at the household level, and more specifically from mothers and fathers, covering basic socio-demographic characteristics, wealth, child caring practices, healthcare access, maternal and paternal education, income and credit practices, water and sanitation, food consumption patterns; demographics, nutrition and health status data at the child level.

To assess nutritional status using anthropometric indicators, weight and height/length were recorded. Children were weighed without clothes. Weight was measured to the nearest 100 grams by trained research assistants using a beam balance ( $<10 \mathrm{~kg}$; Raman Surgical Co., Delhi-33, India) and an electronic balance for those children heavier than $10 \mathrm{~kg}$. For children younger than 2 years of age, length measurements were taken to the nearest millimeter in recumbent position with an infantometer (Narang Medical, Delhi-110 028, India). If children were older than 2 years, they were measured standing up with an adjustable board calibrated in millimeters. Each research assistant measured and weighted each child twice to minimize measurement errors and use the average value of both measurements to gain precision. These instruments were calibrated daily.

Study questionnaires were administered by twelve experienced research assistants (Rodriguez-Llanes et al., 2011) from the Voluntary Health Association of India (VHAI) who received specific training on anthropometry and interview procedures for this study in late August 2009. The questionnaire was piloted in 12 households ( 6 in flooded villages and 6 in non-flooded) and improved based on the inputs of the pilot exercise. The study questionnaire was translated to the local language in Odisha (Oriya) and subsequently back translated into English by different professional translators and a researcher checked the level of agreement between both versions. Duration of interviews ranged from 45 to 60 minutes and all field work was completed between 6 and 24 September 2009.

\section{Study variables}


190 As our aim was to estimate the association effect of formal maternal and paternal education on child

191 undernutrition we excluded variables in our dataset which may have mediated this effect (Schisterman,

192 Cole \& Platt, 2009). We supported our choice by examining these variables (eg, caregiving practices,

193 food security, and access to health care, water and sanitation) framed within the UNICEF framework for

194 child malnutrition (UNICEF, 1997). Overall 51 variables were assessed in a previous study (Rodriguez-

195 Llanes et al., 2016) but for the purpose of this study we only analyzed distal determinants of child 196 undernutrition.

197 Two outcomes were used in our study: stunting (height-for-age) and wasting (weight-for-height).

198 Stunting is an indicator of chronic malnutrition, whereas wasting often evaluates acute nutritional stress 199 at individual and population levels. The new WHO standard, was used to calculate the z scores for these 200 indicators. Malnutrition was a binary variable indicating whether a children is malnourished, z score $<-2$

201 (1) or not (0) at the time of the interview.

202 Overall, 17 variables were examined as potential predictors. The two fundamental variables of this study 203 were the level of formal education attained by both children's parents, mother and father. Formal 204 education was the only assessed in this study, as we excluded parents with technical training or 205 professional studies (Fig. 2). We studied education using the same categories as recorded in the original 206 questionnaire, which follow benchmarks in the Indian educational system: never attended school (0 207 years of schooling), completed elementary school (5 years of schooling), middle school (8 years), high 208 school (12 years) and completed university studies (15 years or more). For mothers, age at marriage, age 209 at first delivery and age at birth of the selected child were reported and analyzed in years; the later 210 calculated by subtracting the age of each child (converted to years) to the mother's age. Father's age at

211 birth of the selected child was obtained by same calculations. Child's sex was a binary variable. The age

212 of each child in months was obtained from birth certificates and vaccination cards. If these were not 213 available, local calendars were used. The birthweight of each child was recorded in grams from birth 214 certificates and for analytical purpose we expressed birthweight per 100 grams. The count of children 215 younger than 5 years living in a household were used in our analyses. The principal means of livelihood 216 were dichotomized as agriculture (taken as reference), grouping households dedicated to fishing,

217 livestock rearing and crop farming versus non-agricultural for any other reported activity. Two religions 218 were present in the study area: Hinduism, taken as the reference group, and Islam. The caste of the 219 household was based on the household head and was grouped as a scheduled caste, other backward 220 class or general class (reference category). The general class is the higher caste status. The scheduled 
221 caste is the social group historically subject to the higher deprivation levels in the country. Owned land

222 was originally collected in acres but was expressed in hectares and analyzed as a continuous variable.

223 Annual household income was recalculated per capita using data on household size and expressed per

224 1,000 Indian rupees (INR) and modeled as a continuous predictor. A household owning any livestock,

225 including chicken, were modelled against those households not owning any. Finally, we recorded the

226 exact number of persons residing in each household (household size) but were dichotomized as more

227 than 4 or otherwise to account for overcrowding as done by a previous study (Semba et al., 2008). The

228 levels of occupation (employed, unemployed or working as housewife) of mother and father were

229 examined to better comprehend the level of gender empowerment within the household.

\section{Statistical methods}

231 Two expert data managers entered the data. An external researcher (JMR) run exploratory data analysis

232 to identify errors in data entry and other implausible values (Day, Fayers \& Harvey, 1998). ENA for

233 SMART software (version November 2008) was used to calculate nutritional indicators with the 2006

234 World Health Organization Standard (ENA, 2008). ENA software is built up with specific functions for

235 detection of outliers and impossible values. These were used to identify further problematic values

236 among the calculated nutritional indicators. Each potential error discovered was discussed and

237 investigated to determine where they originated and subsequently corrected.

238 The main predictor in this study was mother and father education. The original sample size was

239 determined based on requirements of a previous study (Rodriguez-Llanes et al., 2016). Regarding the

240 main research question addressed by this report, overall, available sample sizes were sufficient for

241 subgroup analyses to detect prevalence ratios of 2 or more with a 80\% power (Sullivan, Dean \& Soe,

242 2009).

243 We examined the relationship between parental education and child nutritional status separately in

244 repeatedly flooded and non-flooded cohorts. A first consideration was not to model maternal and

245 paternal education jointly, but in separate analyses (Fig. 2). Intuitively, individuals with similar education

246 tend to get married more often and this was reflected by our data: variance inflation factor (VIF) did

247 show these two variables being highly collinear. As such, 8 models were fitted on this data ( 2 datasets $x$

2482 outcomes $\times 2$ predictors each). These models are summarized in Fig. 2. 
249 Bivariate and multiple adjusted logistic regression models with a quasi-binomial distribution to control

250 for overdispersion were fitted (Lumley, 2010). For multivariate models, we included only variables with $251 \mathrm{p}<0.1$ in bivariate associations with undernutrition. We first run a full model with all variables having a

252 p-value lower than 0.1, a bit more conservative that some authors recommend (Vittinghoff et al., 2005).

253 On each full model, the VIF on each predictor was calculated and predictors with the highest VIF were

254 sequentially eliminated until all remaining predictors had a VIF lower than 4. Backward selection was

255 then applied to the remaining variables. At each step the non-significant variable with the largest $p$ -

256 value was excluded to obtain a final model including only significant variables at alpha level of $5 \%$ (ie, p-

257 value $<0.05$ ). As proposed in recent literature (Siri, 2014; Muttarak \& Lutz, 2014), we examined the

258 impact of household annual per capita income on the effects on paternal education to ensure that

259 education and income are independent contributors of child nutrition outcomes. We did that in all 8

260 models.

261 Results were provided as prevalence ratios, crude [PR] or adjusted [aPR] with 95\% confidence intervals.

262 Given the limits of our sample size, interactions were not examined. All tests were two-tailed with $\alpha=$

263 0.05. All analyses were weighted. Weights were calculated as the inverse of the selection probabilities.

264 Statistical analyses were conducted in R (version 3.0.2)(R Development Core Team, 2008) with the

265 survey package (Lumley, 2010).

266 Results

\section{Study sample}

268 A sample representative of the children population 6 to 59 months of age was obtained in 265 villages of

269 Jagatsinghpur district. Our analyses excluded children with missing observations on relevant variables

270 and from villages inundated in September 2008 but not in 2006. Fig. 2 provides further details on each

271 stage of the sampling and exclusions before statistical analysis.

272 Table 1 presents descriptive information for the variables analyzed in recurrently flooded communities

$273(n=299)$ and those non-flooded $(n=385)$. Mother's illiteracy was less prevalent in flooded areas

274 compared to non-flooded. Whereas more mothers completed middle school in flooded communities,

275 more completed university studies in non-flooded ones. The percentage of fathers completing high

276 school was $10 \%$ higher in flooded communities compared to non-flooded, while those having university

277 degrees was similar. In general the flooded population was more educated relative to the non-flooded, 
278 and fathers were more educated than mothers. Almost $75 \%$ of the mothers attained at least middle

279 school amongst the flooded villages relative to $67 \%$ in the non-flooded. For a similar comparison

280 amongst fathers, the percentages were higher, $89 \%$ and $81.2 \%$, respectively.

281 Flooded households showed higher reliance on agriculture activities as per their higher percentages of

282 land and livestock owned, which corresponded to higher proportions dedicated to agricultural activities

283 (41.8\% in flooded vs $35.8 \% \%$ in non-flooded). Households of the highest cast were also more common in

284 the sample of flooded villages whereas schedule and other backward castes were found more often in

285 non-flooded communities. Unemployment rates among fathers were $2.1 \%$ in non-flooded compared to

$2862.3 \%$ in recurrently-flooded populations. As many as $97.7 \%$ of all interviewed mothers worked as

287 housewives in both flooded and non-flooded communities.

288 Figure 2: Flow diagram of sampling procedure, sample obtained and analyses undertaken. 
265 villages in Jagatsinghpur district from 4

severely affected blocks with estimated 17,876

children aged 6 to 59 months (sampling frame)

9,025 in 122 flooded villages (FV)

8,851 in 143 non-flooded villages (NFV)

30 clusters in 29 villages selected using PPS

sampling with replacement (first sampling stage)

15 clusters in $14 \mathrm{FV}$

15 clusters in 15 NFV

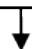

29 selected villages screened and 3,671 eligible

children listed

1,733 children in FV

1,938 children in NFV

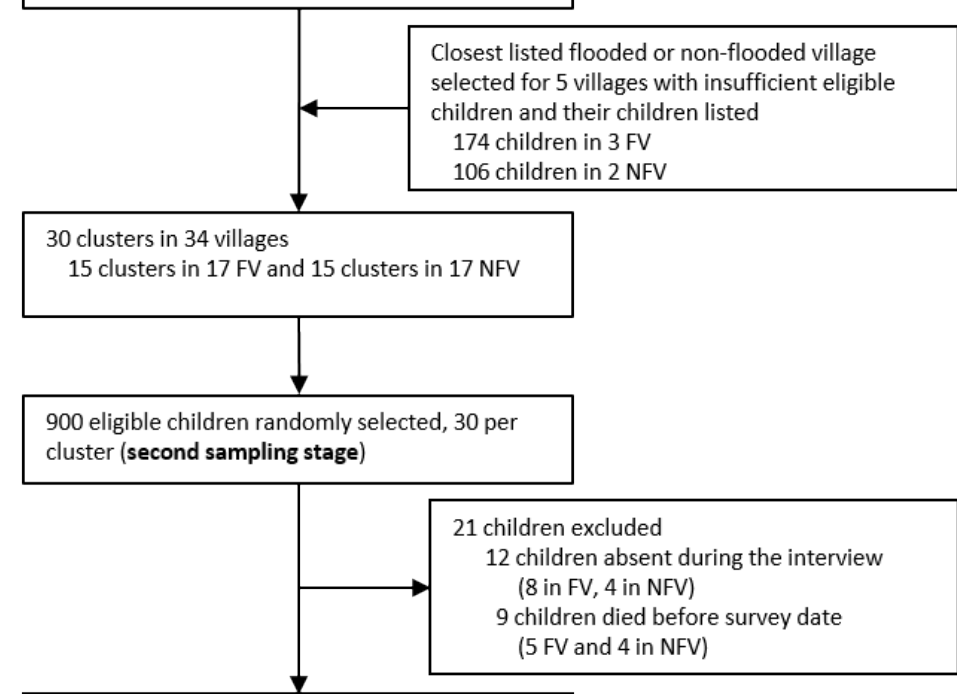

879 children measured and weighted (437 in FV

442 in NFV)

871 heads of household completed interview

299 records from children in flooded villages in 2006 and 2008 analyzed

1a: maternal edu.

1b: paternal edu.

\begin{tabular}{|l|}
131 records excluded \\
10 with ages out of range \\
104 from 5 villages not in original PPS \\
1 with WHZ score missing \\
3 with no data on mother's formal education \\
13 with no data on father's formal education
\end{tabular}

748 complete records from children aged 6 to 59

months (analytical phase)

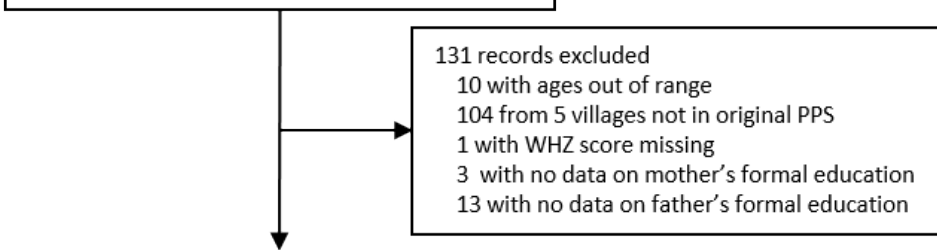

exclusively in 2008 excluded
385 records from children inhabiting non-flooded communities analyzed

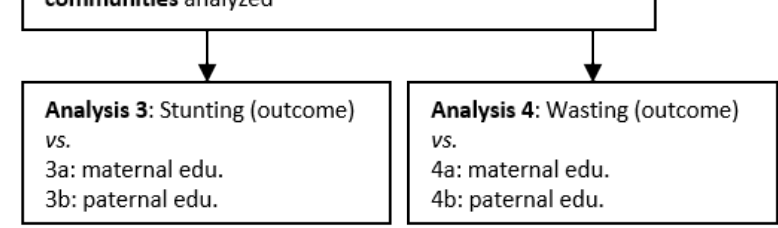


291 Table 1: Prevalence of stunting, wasting and baseline characteristics in rural flooded and non-flooded communities of Odisha, India.

293

\begin{tabular}{|c|c|c|c|c|}
\hline \multirow[b]{2}{*}{ Variables } & \multicolumn{2}{|c|}{ Flooded $(n=299)$} & \multicolumn{2}{|c|}{ Non-flooded $(n=385)$} \\
\hline & $n$ & $\%$ or mean (SE) & $n$ & $\%$ or mean (SE) \\
\hline Stunting & 299 & $30.4(0.03)$ & 385 & $29.0(0.03)$ \\
\hline Wasting & 299 & $51.5(0.03)$ & 385 & $20.3(0.03)$ \\
\hline \multicolumn{5}{|l|}{ Maternal education } \\
\hline None & 17 & $5.4(0.01)$ & 37 & $9.5(0.02)$ \\
\hline Primary school & 59 & $19.9(0.03)$ & 96 & $23.5(0.02)$ \\
\hline Middle school & 106 & $36.0(0.03)$ & 105 & $26.1(0.02)$ \\
\hline High school & 85 & $29.3(0.03)$ & 108 & $28.7(0.03)$ \\
\hline College or more & 32 & $9.3(0.02)$ & 39 & $12.2(0.02)$ \\
\hline \multicolumn{5}{|l|}{ Paternal education } \\
\hline None & 6 & $2.5(0.01)$ & 15 & $4.1(0.01)$ \\
\hline Primary school & 29 & $8.5(0.02)$ & 55 & $14.2(0.02)$ \\
\hline Middle school & 87 & $25.4(0.03)$ & 116 & $29.6(0.03)$ \\
\hline High school & 116 & $41.0(0.03)$ & 123 & $31.0(0.03)$ \\
\hline College or more & 61 & $22.6(0.03)$ & 76 & $21.2(0.03)$ \\
\hline Mean age at marriage of the mother, years & 299 & $21.8(0.18)$ & 385 & $21.5(0.17)$ \\
\hline Mean age of the mother at first delivery, years & 299 & $23.7(0.17)$ & 385 & $23.4(0.17)$ \\
\hline Mean age of the mother at birth of selected child, years & 299 & $26.1(0.24)$ & 385 & $25.9(0.21)$ \\
\hline Mean age of the father at birth of selected child, years & 299 & $31.3(0.27)$ & 385 & $31.1(0.27)$ \\
\hline Mean annual income per household capita, 1,000 rupees & 299 & $7.5(0.60)$ & 385 & $7.3(0.63)$ \\
\hline Means of livelihood linked to agriculture & 299 & $41.8(0.03)$ & 385 & $35.8(0.03)$ \\
\hline Mean land owned, hectares & 299 & $0.6(0.05)$ & 385 & $0.4(0.04)$ \\
\hline Any livestock owned & 184 & $64.7(0.03)$ & 209 & $55.2(0)$ \\
\hline \multicolumn{5}{|l|}{ Religion } \\
\hline Hindu & 248 & $89.9(0.01)$ & 357 & $92.7(0.01)$ \\
\hline Muslim & 51 & $10.1(0.01)$ & 28 & $7.3(0.01)$ \\
\hline \multicolumn{5}{|l|}{ Caste } \\
\hline General & 83 & $33.2(0.03)$ & 68 & $20.5(0.03)$ \\
\hline Other backward & 100 & $32.4(0.03)$ & 183 & $41.9(0.03)$ \\
\hline Scheduled caste & 66 & $24.6(0.03)$ & 106 & $30.3(0.03)$ \\
\hline No caste & 50 & $9.8(0.01)$ & 28 & $7.3(0.01)$ \\
\hline No. of individuals eating from same kitchen $>4$ & 240 & $78.7(0.03)$ & 287 & $76.5(0.02)$ \\
\hline Mean no. of children under five eating from same kitchen & 299 & $1.4(0.04)$ & 385 & $1.5(0.05)$ \\
\hline Child female & 140 & $45.0(0.03)$ & 175 & $44.4(0.03)$ \\
\hline Mean birthweight, 100 grams & 299 & $27.7(0.25)$ & 385 & $27.4(0.21)$ \\
\hline Mean child age, months & 299 & $33.4(1.08)$ & 385 & $32.5(0.97)$ \\
\hline
\end{tabular}

\section{Correlates of child stunting}


296 In univariate analyses, paternal and maternal education played an important role in reducing child

297 stunting (Fig. 3). Overall, the protective effect of education on child stunting were substantial for most 298 educated groups, amongst flooded communities and in men. Compared to mothers never attending 299 school, a 3-fold (200\%) lower prevalence of stunting was observed in most educated ones (ie, those completing university studies). But generally the effects observed on paternal education were larger and stronger compared to maternal education (Fig. 3).

Figure 3: Factors associated to child stunting in repeatedly flooded and non-flooded communities of rural coastal Odisha, India.

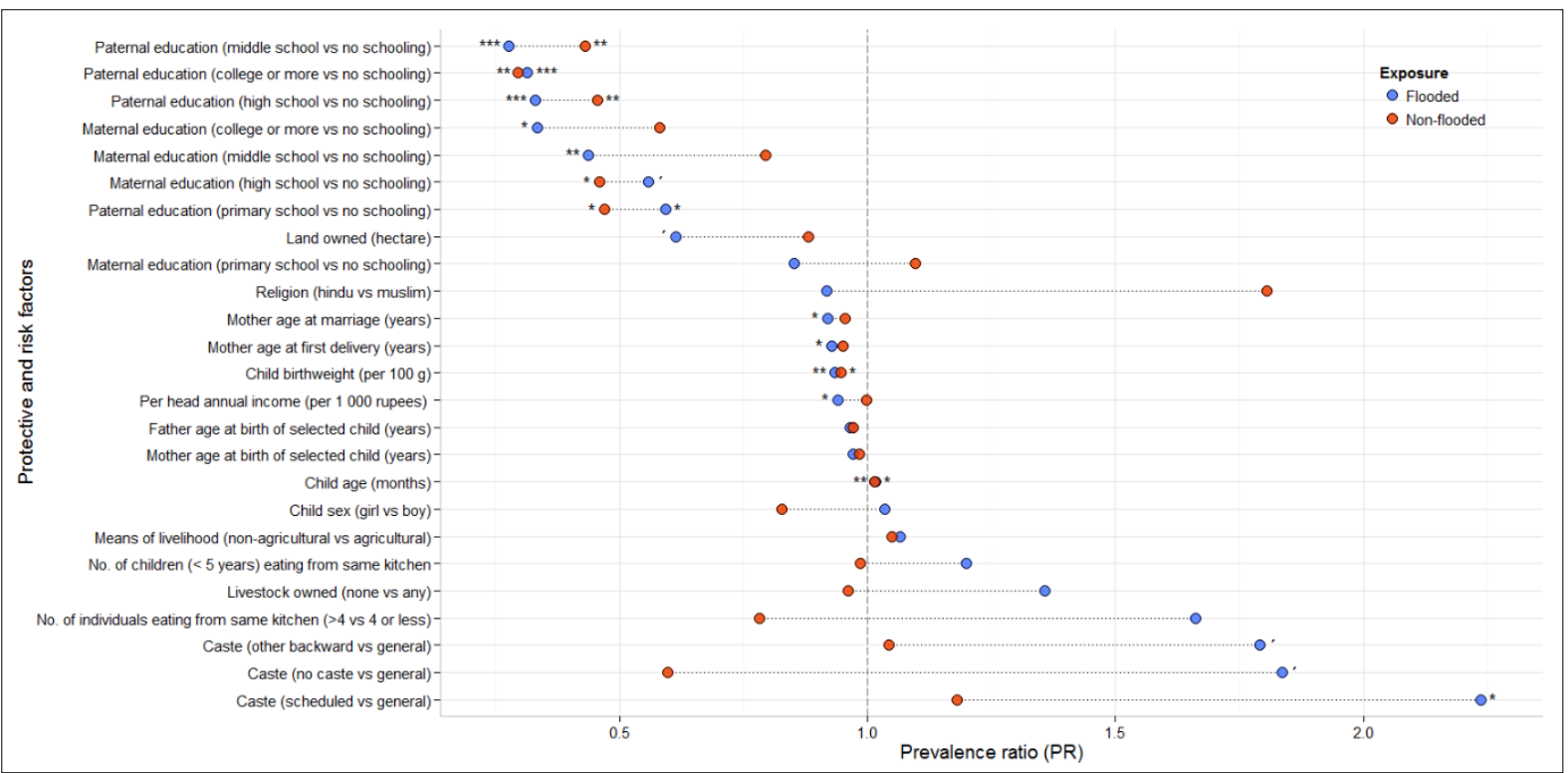

306

307

308

309

310

311

312

313

314

315

316

Blue dots show the prevalence ratios in repeatedly flooded communities. Red dots in non-flooded. Dotted lines show the relative difference in the univariate effects between flooded and unflooded communities. $* * * p<0.001$; ** $p<0.01 ; * p<0.05$, ' $p<0.1$.

An additional hectare of land owned in flooded communities had a substantial protective effect, although non-significant ( $p=0.07$; detailed results in Table S1), but the effect was lower in non-flooded. A per capita household annual income improvement of 1,000 rupees was also associated with a decrease of about $6 \%$ in child stunting, but again, only in flooded households (Fig. 3, Table S1). Belonging to a backward caste was detrimental to child stunting but only in flooded communities, and especially deleterious in the most deprived caste in India, the scheduled caste, with more than a 2-fold associated increase in the prevalence of child stunting. 


\section{Multivariate analyses on child stunting}

319 In adjusted analyses, the positive effect of maternal and paternal education on child nutrition weakened and remained statistically significant only for models on paternal education in flooded communities; and marginally significant in non-flooded (Table 2). In repeatedly-flooded communities, fathers with completed middle, high school or university studies were consistently associated with 2.5-, 2.1- and 2.7fold lower prevalence of child stunting, respectively. In those non-flooded, completed middle or high school by fathers conferred lower protection to their children, with associated 1.9- $(p=0.055)$ and 1.8fold $(p=0.085)$ lower prevalence of stunting but none reached statistical significance. Having completed college was comparably as protective in non-flooded areas as in flooded (2.8-fold reduction), and the effect statistically significant $(p=0.015)$.

Per capita annual income was a consistent effect in flooded studied areas and across models on maternal and paternal education with $4.7 \%$ to $4.9 \%$ lower prevalence of stunting for each yearly increase in 1,000 rupees per capita at household level. Schedule caste remained a relevant factor in multivariate analysis modeling the effect of maternal education but only in flooded communities (Table 2). The two final models for non-flooded-communities were also adjusted for the effect of income but no substantial change in the coefficients were noted. 
347 Table 2: Multivariate logistic regression models for maternal and paternal education and further risk 348 factors associated to stunting in flooded and non-flooded children populations in rural Odisha, India.

\begin{tabular}{|c|c|c|c|c|}
\hline & \multicolumn{2}{|c|}{ Flooded $(n=299)$} & \multicolumn{2}{|c|}{ Non-flooded $(n=385)$} \\
\hline Models for maternal education & aPR $(95 \% \mathrm{Cl})$ & $p$-value & aPR $(95 \% \mathrm{Cl})$ & $p$-value \\
\hline Maternal education & .. & .. &.. &.. \\
\hline No schooling & 1 & .. & 1 & .. \\
\hline Primary school & $0.895(0.558,1.434)$ & 0.645 & $1.275(0.657,2.475)$ & 0.473 \\
\hline Middle school & $0.572(0.335,0.978)$ & 0.042 & $0.927(0.461,1.866)$ & 0.832 \\
\hline High school & $0.839(0.468,1.504)$ & 0.556 & $0.523(0.242,1.127)$ & 0.099 \\
\hline College or more & $0.598(0.228,1.567)$ & 0.296 & $0.717(0.263,1.954)$ & 0.516 \\
\hline Child age (months) & $1.015(1.003,1.027)$ & 0.014 & $1.015(1.004,1.026)$ & 0.008 \\
\hline Caste & .. &.. &.. &.. \\
\hline General & 1 & .. & NA & NA \\
\hline Other backward & $1.654(0.864,3.164)$ & 0.130 & NA & NA \\
\hline Scheduled caste & $2.007(1.068,3.770)$ & 0.031 & NA & NA \\
\hline No caste & $1.560(0.772,3.151)$ & 0.216 & NA & NA \\
\hline Per head annual income (per 1,000 rupees) & $0.955(0.913,0.998)$ & 0.043 & NA & NA \\
\hline \multicolumn{5}{|l|}{ Models for paternal education } \\
\hline Paternal education &.. &.. &.. &.. \\
\hline No schooling & 1 & .. & 1 & .. \\
\hline Primary school & $0.779(0.478,1.268)$ & 0.315 & $0.523(0.260,1.052)$ & 0.070 \\
\hline Middle school & $0.404(0.247,0.661)$ & $<0.001$ & $0.530(0.278,1.012)$ & 0.055 \\
\hline High school & $0.487(0.300,0.624)$ & 0.004 & $0.563(0.293,1.081)$ & 0.085 \\
\hline College or more & $0.372(0.205,0.791)$ & 0.047 & $0.360(0.159,0.816)$ & 0.015 \\
\hline Child age (months) & $1.013(1.001,1.024)$ & 0.033 & $1.012(1.001,1.023)$ & 0.035 \\
\hline Child birthweight (per 100 grams) & NA & NA & $0.950(0.905,0.997)$ & 0.037 \\
\hline Per head annual income (per 1,000 rupees) & $0.953(0.911,0.996)$ & 0.032 & NA & NA \\
\hline
\end{tabular}

NA, results not available if variable not retained in multivariate model.

Correlates of child wasting

351 Crude associations showed an important role of parental education to reduce child wasting, with a preponderance of paternal over maternal effects of formal education and the largest effects observed in non-flooded communities (Fig. 4). An association between means of livelihood (non-agriculture vs agriculture) and child wasting favoring households not relying on agriculture activities was observed, with a $47 \%$ lower prevalence of child wasting compared to those dedicated to agricultural activities (Fig. 4, detailed results in Table S2). 


\section{Multivariate analyses on child wasting}

359

In flooded communities, the protective effects of different levels of paternal education were all

The results for paternal education were different in adjusted models compared to those showed by bivariate associations (Table 3, Table S2, Fig. 4).

Figure 4: Factors associated to child wasting in repeatedly flooded and non-flooded communities of rural coastal Odisha, India.

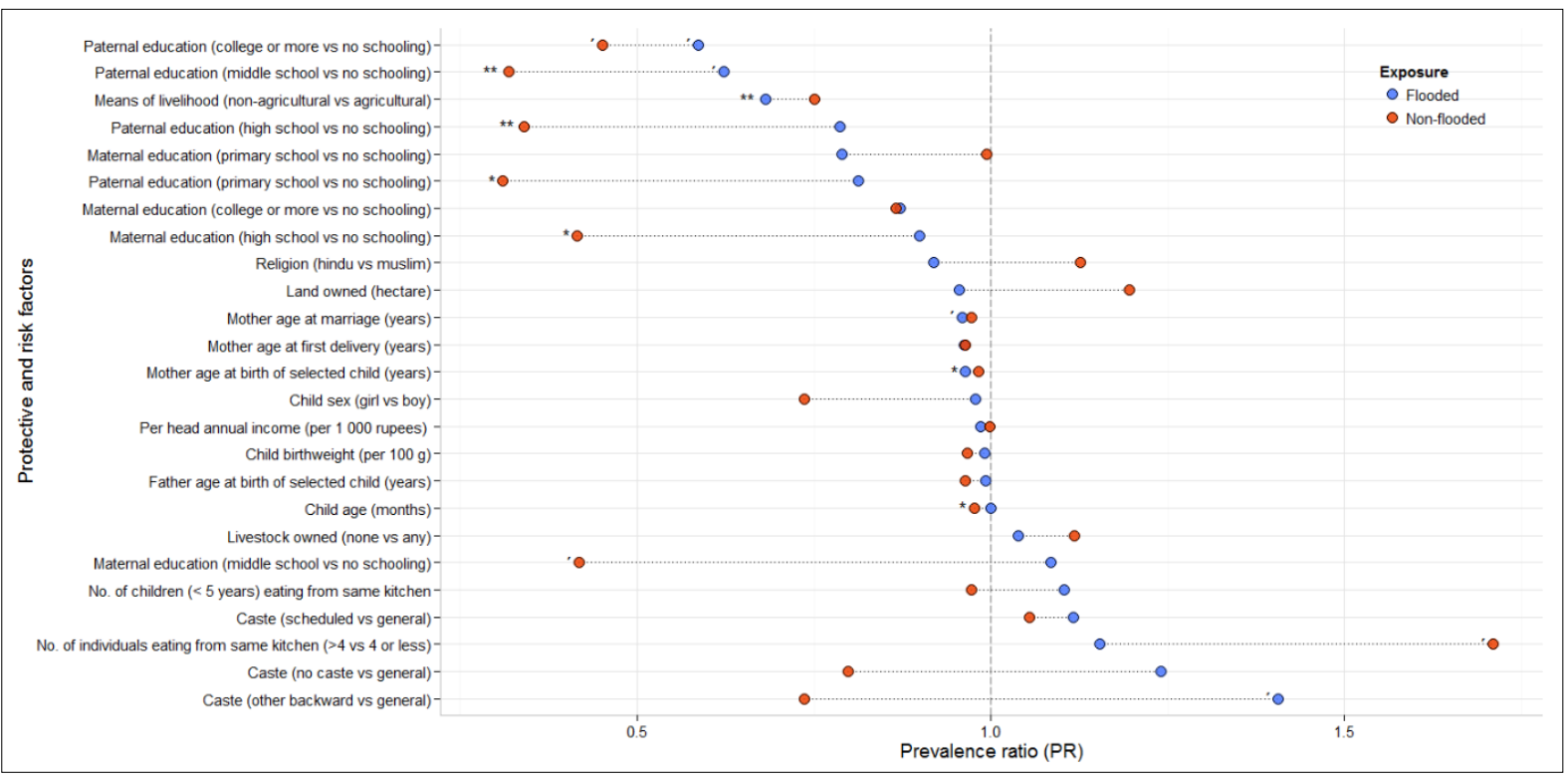

Blue dots show the prevalence ratios in repeatedly flooded communities. Red dots in non-flooded. Dotted lines show the relative difference in the univariate effects between flooded and unflooded communities. ${ }^{* *} p<0.01$; * $p<0.05, ' p<0.1$. significant $(p<0.001)$ except for that of primary education $(p=0.117)$. However, larger effects were observed in the non-flooded communities surveyed in our study starting from primary education (2.9fold lower prevalence, $p=0.019)$, middle (2.9 times lower, $p=0.012$ ) or high school (2.7-fold difference,

374 wasting among their children, though the association remained insignificant $(p=0.081)$. In flooded

375 households dedicated to activities other than agriculture, a 50 to $51 \%$ lower prevalence of child wasting was estimated (Table 3). 
377 In modeling the effect of maternal education in flooded communities, we found that mother's age at

378 birth of the studied child was associated with an improved nutritional outcome of their children. Each

379 additional year was associated with a $3.4 \%$ lower prevalence of wasting ( $p=0.005$; Table 3 ). In flooded

380 communities only and for the model on maternal education, belonging to other backward castes

381 showed to be deleterious on child wasting (Table 3). All four final models in this section were also

382 adjusted for annual per head income but none of those inclusions impacted our results.

Table 3: Multivariate logistic regression models for maternal and paternal education and further risk factors associated to wasting in flooded and non-flooded children populations in rural Odisha, India.

\begin{tabular}{|c|c|c|c|c|c|}
\hline & & \multicolumn{2}{|c|}{ Flooded $(n=299)$} & \multicolumn{2}{|c|}{ Non-flooded $(n=385)$} \\
\hline \multicolumn{2}{|c|}{ Models for maternal education } & aPR $(95 \% \mathrm{Cl})$ & $p$-value & aPR $(95 \% \mathrm{Cl})$ & $p$-value \\
\hline \multicolumn{2}{|c|}{ Maternal education } & .. & .. & .. & .. \\
\hline & No schooling & 1 & .. & 1 & .. \\
\hline & Primary school & $0.817(0.531,1.257)$ & 0.359 & $0.819(0.435,1.542)$ & 0.536 \\
\hline & Middle school & $1.013(0.730,1.407)$ & 0.939 & $0.338(0.157,0.728)$ & 0.006 \\
\hline & High school & $0.858(0.598,1.231)$ & 0.406 & $0.360(0.178,0.726)$ & 0.005 \\
\hline & College or more & $0.975(0.609,1.563)$ & 0.917 & $0.637(0.247,1.643)$ & 0.351 \\
\hline \multicolumn{2}{|c|}{ Mother age at birth of selected child (years) } & $0.967(0.944,0.989)$ & 0.005 & NA & NA \\
\hline \multicolumn{2}{|c|}{ Means of livelihood (non-agricultural vs agricultural) } & $0.660(0.526,0.828)$ & $<0.001$ & NA & NA \\
\hline \multicolumn{2}{|c|}{ Child age (months) } & NA & NA & $0.975(0.956,0.994)$ & 0.009 \\
\hline \multicolumn{2}{|l|}{ Caste } & .. & .. & .. & .. \\
\hline & General & 1 & .. & NA & NA \\
\hline & Other backward & $1.396(1.016,1.917)$ & 0.040 & NA & NA \\
\hline & Scheduled caste & $1.272(0.887,1.826)$ & 0.191 & NA & NA \\
\hline & No caste & $1.393(0.913,2.130)$ & 0.125 & NA & NA \\
\hline \multicolumn{2}{|c|}{ Number of individuals eating from same kitchen } & .. & .. & .. & .. \\
\hline & 2,4 & NA & NA & 1 & .. \\
\hline & $>4$ & NA & NA & $1.870(1.059,3.301)$ & 0.032 \\
\hline \multicolumn{6}{|c|}{ Models for paternal education } \\
\hline \multicolumn{2}{|c|}{ Paternal education } & .. & .. & .. & .. \\
\hline & No schooling & 1 & .. & 1 & .. \\
\hline & Primary school & $0.777(0.567,1.064)$ & 0.117 & $0.348(0.144,0.840)$ & 0.019 \\
\hline & Middle school & $0.571(0.432,0.754)$ & $<0.001$ & $0.349(0.155,0.787)$ & 0.012 \\
\hline & High school & $0.699(0.579,0.844)$ & $<0.001$ & $0.366(0.175,0.763)$ & 0.008 \\
\hline & College or more & $0.521(0.363,0.750)$ & $<0.001$ & $0.490(0.220,1.090)$ & 0.081 \\
\hline \multicolumn{2}{|c|}{ Means of livelihood (non-agricultural vs agricultural) } & $0.667(0.526,0.846)$ & $<0.001$ & NA & NA \\
\hline \multicolumn{2}{|c|}{ Child age (months) } & NA & NA & $0.977(0.958,0.997)$ & 0.023 \\
\hline
\end{tabular}




\section{Discussion}

389 This study identifies education as one key investment in reducing the health impacts of extreme events 390 under climate change risks while promoting sustainable human development. The most striking finding 391 is that paternal, and not maternal education, appeared to be the strongest predictor of lower child 392 stunting and wasting in these communities. In non-flood settings, large samples from Indonesia and 393 Bangladesh studied the effect of parental education on child stunting, and comparable positive effects were found for maternal and paternal education (Semba et al., 2008). The effect of paternal education on child wasting and stunting was found to be comparable to that of mothers' also in India and Vietnam (Moestue \& Huttly, 2008). In flood settings, however, these effects were not as clear as in available studies. Hossain \& Kolsteren (2003) found no effect of mother education on child wasting recovery four months after large floods in Bangladesh. Also in Bangladesh, Del Ninno \& Lundberg (2005) found no effect of maternal education on child growth between three waves of anthropometric data collected within 15 months after the floods. None of these studies considered the effect of paternal education.

401

In our specific setting, we hypothesize that the observed differences in effects favoring paternal education could be partly explained by the low economic independence of women in our sample: nearly $98 \%$ of mothers in both exposure groups were housewives and we assumed had no revenues. We acknowledge that this topic is complex and more studies on this specific interaction should be conducted on datasets having larger samples than ours. However, in India evidence exist pointing to low maternal economic and physical autonomy as a contributor to child stunting (Shroff et al., 2009; Imai et al., 2014).

A second observation is that the effect of paternal education on child stunting were larger and statistically significant in flooded communities while the same estimated effects in non-flooded communities were of smaller magnitude. It looks as if the already positive effect of education might be boosted in a post-flood situation. Several studies have shown that education might substantially improve coping after disasters, through avoiding income loss after a disaster (Garbero \& Muttarak, 415 2013), diversification of economic activites (van der Land \& Hummel, 2013) or choosing sustainable 416 mechanisms for coping prevail over short-term views (Wamsler, Brink \& Rantala, 2012; Helgeson, Dietz $417 \&$ Hochrainer-Stigler, 2013). In a disaster situation, decisions on allocation of the constraint resources 418 available can be crucial. More educated parents might be able to invest in coping strategies with longer 
419 term benefits, have more savings or simply work in professions which are less affected by floods. Our

420 results on child wasting showing that non-agricultural livelihoods withstood better the shock caused by

421 flooding reinforce this point. Similar results on a higher likelihood of post-disaster migration in low

422 educated farmers are consistent with our views (van der Land \& Hummel 2013). Crop farming, livestock

423 rearing and fishing were the most affected activities according to reports from the Government of

424 Odisha: around half the production of the 0.44 Million Kharif crops flooded were lost, more than 2.3

425 Million livestock flood-affected, and above 6,300 fishing boats with their nets and other equipment 426 damaged (Government of Orissa, 2008). Our findings are consistent with this pattern of affectedness

427 and reveal their mid-term consequences on child nutritional health. Young children of agricultural

428 livelihoods were the most impacted regarding the prevalence of wasting one year after the floods,

429 which was around 50\% higher than in other livelihoods. Importantly, no effect was observed for similar

430 analyses conducted in non-flooded communities, whether univariate or multivariate. This reinforces the

431 hypothesis that crop destruction and overall food insecurity is a very likely pathway to child

432 undernutrition among the flooded populations (Leaning \& Guha-Sapir 2013). There is much to do to in

433 terms of mitigation strategies to reduce the initial impact of floods on the livelihoods of these vulnerable

434 populations. At the same time, there is an urgent need to reform and expand the relief response, which

435 was not commensurate to the magnitude and duration of the problem. The basic needs of the affected

436 were only covered by the government on the first 15 days following the floods. We need to ensure that

437 these livelihoods are satisfied on around a year after the floods and that we target most affected

438 livelihoods. Crops take months to be harvested since they are planted. Animal stocks need time to

439 recover fully, same for repairing boats or buying new ones. Without more dedicated resources, the risk

440 is on perpetuating poverty cycles.

441

442 Another consistent result was the positive effect of income on child nutrition in flood-affected

443 communities. For example, an increase in 5,000 rupees per capita in yearly income within households

444 should be associated with $25 \%$ lower prevalence of child stunting. Sustainable livelihood economic

445 development is then a plausible strategy to reduce the nutritional burden of floods according to our

446 data. In contrast, and again in flood-affected livelihoods only, lower caste was associated with worst

447 nutritional status for both wasting and stunting variables, suggesting that caste is still in association with

448 lower opportunities. Our study findings show that these social determinants of different impacts get

449 visible in an extreme situation such as a disaster but we were unable to offer an explanation on the

450 mechanism explaining this pattern in the data. Qualitative research might plausibly be very useful to 
451 investigate the reasons further. Finally, an important result was that mothers giving birth later had a 452 lower likelihood of having a wasted children. Our model suggest that by delaying 5 years the birth of a 453 given child, the associated prevalence of child wasting in case of floods would be on average $17 \%$ lower.

454 It is noteworthy to point that this result was independent from the effect of mother education, adjusted

455 for in this model.

456

457 Taking all the above together, education promotion in rural areas, especially among women, would be 458 extremely efficient. In our study area about $30 \%$ of the mothers did not completed middle school 459 education, which is mandatory in India. There is also an education gap with men in our study area, for 460 whom this percentage was less than $20 \%$, a $10 \%$ difference with women. It is worth mentioning that 461 looking across all models in our study, primary education (up to 11 years of age) was not a significant 462 contributor to better child nutrition in 7 out of 8 models reported. However, providing 3 additional years 463 of schooling (up to 14 years) had a significant positive impact on child nutrition. Moreover, the 464 magnitude of effects reported for middle, high and college education were quite comparable, suggesting 465 that at least in these rural communities, middle education is sufficient. Our results are in agreement 466 with the Indian policy on education. More efforts are then needed to ensure that every Indian children 467 receives the 8 years of compulsory formal education. By promoting more education and adequate family 468 planning (Van Braeckel et al., 2012), women might naturally delay motherhood, with potential benefits 469 to children's nutritional health. To ensure full benefits, we hypothesized that mother education might 470 lead to increased employment rates amongst women, as this would also contribute to additional higher 471 household income (with associated benefits shown by our study). Notably, it has been demonstrated 472 that income allocation by mothers is more efficient to improve family's health, including child nutritional 473 status, compared to fathers (Thomas, 1990).

475 Strengths and limitations of the study

476 There a few methodological considerations, strengths and limitations that need to be addressed here.

477 Firstly, all the reported results were adjusted, as an additional robustness check, by annual per capita 478 household income. As such all effects reported were independent of income, and thus our results can be 479 methodologically comparable to those recently published (Muttarak \& Lutz, 2014). Second, we often 480 found in the literature maternal and paternal education jointly modelled (Semba et al., 2008). However, 481 we found that these two variables were highly correlated in our data and enough evidence using 482 variance inflation factor analysis, which supported that they should be modelled separately. Future 
483 studies should be aware of this. Third, father education was highly correlated to caste and mother's age

484 at birth of a child, and this is the reason why models modeling father education do not include these 485 variables. Strengths of this study include carefully consideration of income, as well as having analyzed 486 data on a non-flooded group which allowed us to observe that some effects such as mother's age at 487 birth, income or caste become important determinants only in the extreme circumstances of flooding.

488 Additional positive features of this study were its population-based design, the consideration of 489 recurrently flooded communities only, coupled with the analysis of mid-term and more long-term child 490 undernutrition. On the minus side, our study was not based on a very large sample size, which could 491 have been missed the detection of smaller effects and provided tighter confidence intervals. Similarly a 492 larger sample size might have allowed us to analyze most severe forms of malnutrition, such as severe 493 wasting and stunting. In the aftermath of flooding in Bangladesh, Choudhury \& Bhuiya (1993) have 494 shown maternal education to play a role in increasing severe forms of underweight. Also, as the findings 495 presented are based on cross-sectional data, care is needed to not attribute causal relationships to the associations showcased here. Importantly, it is difficult to generalize our results to other settings such as urban slums, as vulnerabilities might be different there. However, we are confident that there might be similarities between our results and other rural areas around the world in which subsistence farming is the norm. With its limitations, this is one of the first studies to look at child undernutrition in flood settings and study potential preventive factors in short and long-term. More studies are needed to

501 solidify the evidence base for global action.

502

503

\section{Conclusions}

504 We recommend strengthening the response to floods and targeting most vulnerable agriculturaldependent livelihoods, which showed an associated $50 \%$ higher prevalence of child wasting. Policies for relief should be reviewed to ensure a longer period of support and proper take up by development programs, which should give enough time and support to these households relying on agricultural activities to fully recover. Education promotion in general and the strict fulfillment of schooling until the compulsory 14 years of age is strongly recommended to protect child's health in the face of future flooding. Policies effectively

511 helping sustainable livelihood economic development and diversification of economic activities, delayed motherhood, which certainly include education promotion, are vividly praised. 
513 Given that global climate changes are set to increase flooding both in frequency and severity which will

514 further aggravate this situation, we recommend urgent action to be taken (UNICEF, 2014).

515

516 Acknowledgments

517 We are grateful to Jean Macq, Niko Speybroeck, Sophie Vanwambeke and Philippe Donnen for comments 518 and guidance. We are grateful to Pascaline Wallemacq for preparing the map.

519

520

521

522

523

524

525

526

527

528

529

530

531

532

533

534 


\section{References}

536 Ahern M, Kovats RS, Wilkinson P, Few R, Matthies F. 2005. Global health impacts of floods:

537 epidemiologic evidence. Epidemiological Reviews 27:36-46

538 Alderman K, Turner LR, Tong S. 2012. Floods and human health: a systematic review. Environment 539 International 47:37-47

540 Black RE, Victora CG, Walker SP, Bhutta ZA, Christian P, de Onis M, Ezzati M, Grantham-McGregor S,

541 Katz J, Martorell R, Uauy R. 2013. Maternal and child undernutrition and overweight in low-income and

542 middle-income countries. Lancet 382: 427-451

543 Bouzid M, Hooper L, Hunter PR. 2013. The effectiveness of public health interventions to reduce the 544 health Impact of climate change: a systematic review of systematic reviews. PLoS ONE 8(4): e62041

545 Choudhury AY, Bhuiya A. 1993. Effects of biosocial variables on changes in nutritional status of rural 546 Bangladeshi children, pre- and post-monsoon flooding. Journal of Biosocial Science 25(3):351-357

547 Day S, Fayers P, Harvey D. 1998. Double data entry: what value, what price?. Controlled Clinical Trials 548 19(1): 15-24

549 Del Ninno C, Lundberg M. 2005. Treading water. The long-term impact of the 1998 flood on nutrition in

550 Bangladesh. Economics and Human Biology 3:67-96.

551 EM-DAT: The OFDA/CRED International Disaster Database. Available at:

552 http://www.emdat.be/database (accessed 15 November 2015)

553 Emergency Nutrition Assessment (ENA). Software for standardized monitoring and assessment of relief 554 and transitions (SMART), version November 2008. Available at:

555 http://www.nutrisurvey.de/ena/ena.html (accessed November 2010)

556 Garbero A, Muttarak R. 2013. Impacts of the 2010 droughts and floods on community welfare in rural

557 Thailand: differential effects of village educational attainment. Ecology and Society 18(4): 27.

558 http://dx.doi.org/10.5751/ES-05871-180427

559 Government of Orissa. 2008. Memorandum on floods 2008. Orissa, India: Special Relief Commissioner, 560 Orissa Revenue and Disaster Management Department

561 Groves RM, Fowler FJ, Couper MP, Lepkowski JM, Singer E, Tourangeau R. 2009. Survey methodology.

562 Oxford: Wiley-Blackwell

563 Helgeson JF, Dietz S, Hochrainer-Stigler S. 2013. Vulnerability to weather disasters: the choice of coping

564 strategies in rural Uganda. Ecology and Society 18(2): 2. http://dx.doi.org/10.5751/ES-05390-180202

565 Hossain SM, Kolsteren P. 2003. The 1998 flood in Bangladesh: is different targeting needed during 566 emergencies and recovery to tackle malnutrition?. Disasters 27:172-184. doi:10.1111/1467-7717.00227

567 Imai KS, Annim SK, Kulkarni VS, Gaiha R. 2014. Women's empowerment and prevalence of stunted and 568 underweight children in Rural India. World Development 62:88-105 
569 Leaning J, Guha-Sapir D. 2013. Natural disasters, armed conflict, and public health. New England Journal 570 of Medicine 369(19):1836-1842

571 Lindeboom M, Llena-Nozal A, van der Klauuw B. 2009. Parental education and child health: evidence 572 from a schooling reform. Journal of Health Economics 28(1): 109-131

573 Lowe D, Ebi KL, Forsberg B. 2013. Factors increasing vulnerability to health effects before, during and 574 after floods. International Journal of Environmental Research and Public Health 10(12): 7015-7067

575 Lumley T. 2010. Complex Surveys: A Guide to Analysis Using R. Hoboken, NJ: John Wiley \& Sons

576 Milman A, Frongillo EA, de Onis M, Hwang JY. 2005. Differential improvement among countries in child 577 stunting is associated with long-term development and specific interventions. Journal of Nutrition 578 135:1415-1422

579 Moestue H, Huttly S. 2008. Adult education and child nutrition: the role of family and community. 580 Journal of Epidemiology and Community Health 62(2):153-159

581 Muttarak R, Lutz W. 2014. Is education a key to reducing vulnerability to natural disasters and hence 582 unavoidable climate change? Ecology and Society 19(1):42. http://dx.doi.org/10.5751/ES-06476-190142

583 Odisha State Disaster Mitigation Authority (OSDMA). 2009. Available at: http://www.osdma.org 584 (accessed 3 April 2009)

585 Phalkey RK, Aranda-Jan C, Marx S, Höfle B, Sauerborn R. 2015. Systematic review of current efforts to 586 quantify the impacts of climate change on undernutrition. Proceedings of the National Academy of 587 Sciences of the United States of America 112(33): E4522-9. doi: 10.1073/pnas.1409769112.

588 R Development Core Team. 2008. R: A language and environment for statistical computing. R 589 Foundation for Statistical Computing, Vienna, Austria. Available at: http://www.R-project.org.

590 Ricci JA, Becker S. 1996. Risk factors for wasting and stunting among children in Metro Cebu, 591 Philippines. American Journal of Clinical Nutrition 63(6): 966-975

592 Rodriguez-Llanes JM, Ranjan-Dash S, Degomme O, Mukhopadhyay A, Guha-Sapir D. 2011. Child 593 malnutrition and recurrent flooding in rural eastern India: a community-based survey. BMJ Open 594 1:e000109. doi:10.1136/bmjopen-2011-000109

595 Rodriguez-Llanes JM, Ranjan-Dash S, Mukhopadhyay A, Guha-Sapir D. 2016. Flood-exposure is 596 associated with higher prevalence of child undernutrition in rural eastern India. International Journal of 597 Environmental Research and Public Health (In press)

598 Semba RD, de Pee S, Sun K, Sari M, Akhter N, Bloem MW. 2008. Effect of parental formal education on 599 risk of child stunting in Indonesia and Bangladesh: a cross-sectional study. The Lancet 371:322-328

600 Schisterman E, Cole S, Platt R. 2009. Overadjustment bias and unnecessary adjustment in epidemiologic 601 studies. Epidemiology 20:488-495. doi:10.1097/EDE.0b013e3181a819a1 
602 Shroff M, Adair L, Suchindran C, Bentley M. 2008. Maternal autonomy is inversely related to child 603 stunting in Andhra Pradesh, India. Maternal Child Nutrition 5:64-74

604 Siri J. 2014. Independent associations of maternal education and household wealth with malaria risk in 605 children. Ecology and Society 19(1): 33. http://dx.doi.org/dx.doi.org/10.5751/ES-06134-190133

606 Striessnig E, Lutz W, Patt AG. 2013. Effects of educational attainment on climate risk vulnerability. 607 Ecology and Society 18(1): 16. http://dx.doi.org/10.5751/ES-05252-180116

608 Sullivan KM, Dean A, Soe MM. 2009. OpenEpi: a web-based epidemiologic and statistical calculator for 609 public health. Public Health Reports 124(3): 471-474.

610 The Census of India. 2011. New Delhi, India: The Registrar General \& Census Commissioner, Ministry of 611 Home Affairs, Government of India. Available at: http://www.censusindia.gov.in (accessed 9 September 612 2014)

613 The Census of India. 2001. New Delhi, India: The Registrar General \& Census Commissioner, Ministry of 614 Home Affairs, Government of India. Available at: http://www.censusindia.gov.in (accessed 3 April 2009)

615 Thomas D. 1990. Intra household resource allocation: an inferential approach. Journal of Human 616 Resources 25(4): 635-664.

617 UNICEF Office of Research. 2014. The challenges of climate change: children on the front line. 618 Innocenti Insight, Florence: UNICEF Office of Research

619 United Nations Children's Fund. 1997. The state of the world's children 1998. New York: Oxford 620 University Press for UNICEF. Available at: http://www.unicef.org/nutrition/files/pub sowc98 en.pdf

621 Van Braeckel D, Temmerman M, Roelens K, Degomme O. 2012. Slowing population growth for 622 wellbeing and development. The Lancet 380:84-85.

623 Van der Land V, Hummel D. 2013. Vulnerability and the role of education in environmentally induced

624 migration in Mali and Senegal. Ecology and Society 18(4):14. http://dx.doi.org/10.5751/ES-05830-

$625 \quad \underline{180414}$

626 Vittinghoff E, Glidden DV, Shiboski SC, McCulloch CE. 2005. Regression methods in biostatistics: Linear, 627 logistic, survival, and repeated measures models. New York: Springer

628 Wamsler C, Brink E, Rantala O. 2012. Climate change, adaptation, and formal education: The role of 629 schooling for increasing societies' adaptive capacities in El Salvador and Brazil. Ecology and Society 17(2):

630 2. http://dx.doi.org/10.5751/es-04645-170202

631 48th World medical assembly. 1997. Declaration of Helsinki: recommendations guiding physicians in 632 biomedical research involving human subjects. Journal of the American Medical Association 277:925633 926. doi:10.1001/jama.1997.03540350075038 
